\title{
Binding of the Alkaloid Aristololactam- $\beta$-D-Glucoside and Daunomycin to Human Hemoglobin: Spectroscopy and Calorimetry Studies
}

\author{
Abhi Das and Gopinatha Suresh Kumar* \\ Biophysical Chemistry Laboratory, Chemistry Division \\ CSIR-Indian Institute of Chemical Biology \\ Kolkata 700032
}

\section{Supplementary data}
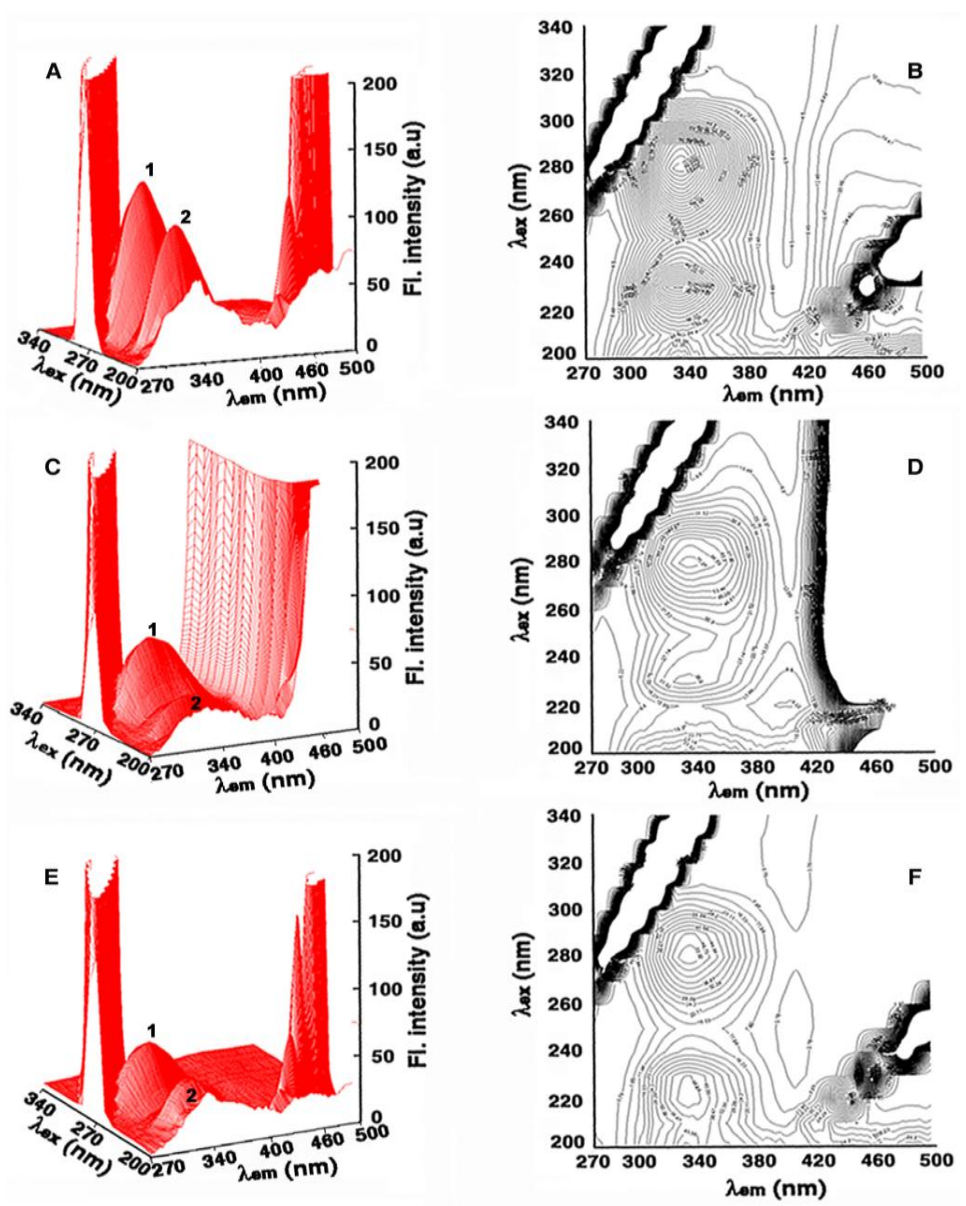

Fig. S1. Three-dimensional fluorescence spectra and contour maps of $\mathrm{Hb}(\mathrm{A}, \mathrm{B}), \mathrm{Hb}-$ ADG complex (C, D) and Hb-DAN complex (E, F). 

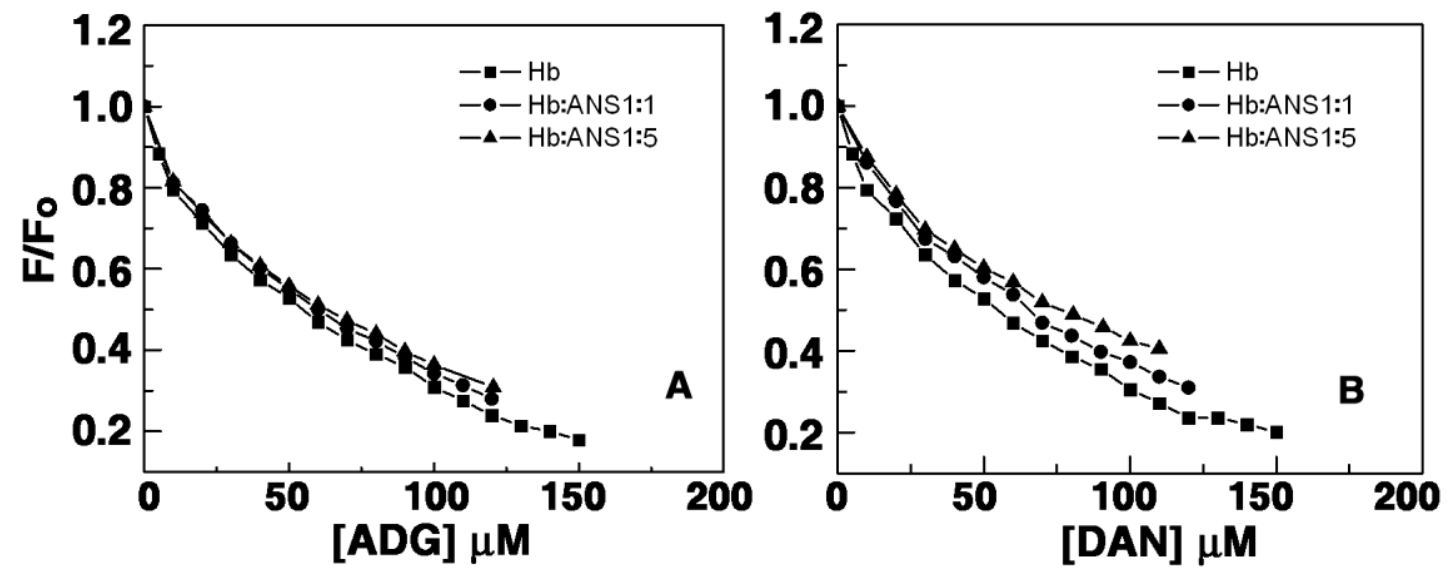

Fig. S2. Displacement study of hydrophobic probe ANS bound to Hb by (A) ADG and (B) DAN. 